\title{
DESAIN SISTEM MANAJEMEN BASIS DATA ASET TETAP PADA SEKOLAH HIGH SCOPE INDONESIA
}

\author{
Hengki Sikumbang \\ Jurusan Teknik Informatika \\ Sekolah Tinggi Teknik PLN Jakarta \\ Email : hengkisikumbang3@gmail.com
}

\begin{abstract}
The development of information technology does not only affect the business world, but also other areas , such as health, education, government and others. Advances in information technology, especially in the era of information also has implications for the management of fixed assets in an entity HighScope Indonesia School is one of the educational institutions from Playgroup through high school located in South Jakarta. Facilities, infrastructure, tools and equipment owned by the HighScope Indonesia School is a fixed asset that must be managed optimally in supporting the operational of education in school HighScope Indonesia.

Management of fixed assets HighScope Indonesia School is still done manually, causing inefficient and ineffective in monitoring fixed assets .

The purpose of this research is to create a design database management system fixed assets. System design by making the Data Flow Diagrams ( DFD ) and Entity Relationship Diagram (ERD).

It is expected that the database management system can well explain all the activity so that desired results in accordance with the wishes of the user and is also expected to minimize the shortcomings and weaknesses of the current system.
\end{abstract}

Keywords : Design, Information System, Data Base, Fixed Asset, Management

\section{ABSTRAK}

Perkembangan teknologi informasi tidak hanya mempengaruhi dunia usaha, tetapi juga bidang - bidang lain, seperti kesehatan, pendidikan, pemerintahan dan lain-lain. Kemajuan teknologi informasi terutama pada era informasi berdampak pula terhadap pengelolaan aset tetap dalam suatu entitas

Sekolah HighScope Indonesia merupakan salah satu institusi pendidikan sejak dari Playgroup sampai SMA yang berada di Jakarta Selatan. Sarana, prasarana, peralatan dan perlengkapan yang dimiliki oleh Sekolah HighScope Indonesia merupakan aset tetap yang harus dikelola secara optimal dalam menunjang kegiatan operasional pendidikan di Sekolah HighScope Indonesia.

Pengelolaan aset tetap Sekolah HighScope Indonesia masih dilakukan secara manual sehingga menimbulkan tidak efisien dan tidak efektifnya dalam monitoring aset tetap.

Tujuan penelitian ini adalah untuk membuat desain sistem manajemen basis data aset tetap. Desain sistem dengan membuat Data Flow Diagram (DFD) dan Entity Relationship Diagram (ERD).

Diharapkan dengan sistem manajemen basis data dapat menjelaskan semua aktivitas dengan baik sehingga hasil yang diinginkan sesuai dengan keinginan pengguna dan diharapkan pula dapat meminimalkan kekurangan dan kelemahan sistem yang ada saat ini.

Kata kunci : Desain, Sistem Informasi, Basis Data, Aset Tetap, Manajemen

\section{Pendahuluan}

Teknologi Informasi (TI) saat ini memberikan banyak manfaat pada berbagai kegiatan usaha Sebuah teknologi yang memusatkan pada pengaturan sistem informasi dengan penggunaan komputer, TI dapat memenuhi kebutuhan informasi dunia usaha dengan sangat cepat, tepat waktu, relevan, dan akurat. Teknologi informasi (TI) turut berkembang sejalan dengan perkembangan peradaban manusia.

Perkembangan TI tidak hanya mempengaruh dunia usaha, tetapi juga bidang - bidang lain, seperti kesehatan, pendidikan, pemerintahan, dan lain-lain. Kemajuan TI juga berpengaruh signifikan pada perkembangan akuntansi yang kegiatannya tidak terlepas dari teknologi informasi tersebut.
Semakin maju $\mathrm{TI}$ semakin banyak pengaruhnya pada bidang akuntansi. Perkembangan teknologi informasi, terutama pada era informasi berdampak pula terhadap sistem informasi akuntansi (SIA) dalam suatu entitas. Dampak yang dirasakan secara nyata adalah pemrosesan data yang mengalami perubahan dari sistem manual ke sistem komputer. Di samping itu, pengendalian intern dalam SIA serta peningkatan jumlah dan kualitas informasi dalam pelaporan keuangan juga akan terpengaruh. Hal ini menjawab keraguan kita atas kemampuan manusia untuk mengolah data dengan baik, sehingga fungsi dan efisiensi hasil pengolahaan data tersebut dapat dipertanggungjawabkan kebenarannya. Akan tetapi, semua perangkat yang mendukung hal tersebut 
tidak akan bekerja secara optimal, jika tidak ditunjang dengan sistem informasi yang baik. Dengan kata lain, arus data yang terjadi dalam sistem informasi harus dirancang dengan baik.

Informasi merupakan hal yang penting dalam pengendalian intern entitas. Informasi merupakan output dari sistem informasi yang ada, yang dikomunikasikan kepada pengguna atau kepada orang-orang yang membutuhkan informasi sehingga informasi tersebut berguna. Informasi dapat menjadi evaluasi atau umpan balik untuk melakukan perbaikan jika terjadi penyimpangan dalam pelaksanaan kebijakan manajemen.

Penerapan informasi yang memadai akan menunjang pengendalian intern yang efektif dapat menghasilkan informasi yang diperlukan oleh pihak manajemen dalam pengambilan keputusan. Sejalan dengan tuntutan era globalisasi maka informasi akuntansi yang dibutuhkan semakin banyak dan kompleks. Hal ini membuat sistem informasi semakin penting. Akibatnya resiko yang membahayakan pengamanan sistem ini pun meningkat. Manajemen harus dapat memastikan bahwa sistem informasi akuntansi yang ada dalam entitas telah dikendalikan secara memadai.

Aset tetap sangat berpengaruh terhadap berbagai kegiatan operasional entitas demi tercapainya efisiensi dan efektivitas kegiatan operasional yang mendukung pencapaian tujuan entitas. Oleh karena itu, diperlukan pengendalian dan pengawasan internal yang begitu besar terhadap aset tetap. Pengendalian dan pengawasan tersebut dilakukan untuk melindungi aset dari pencurian, penggelapan, penyalahgunaan, atau penempatan aset pada lokasi yang tidak tepat. Pengendalian internal juga dapat memberikan jaminan terhadap informasi bisnis yang akurat demi keberhasilan usaha, serta mengupayakan agar karyawan entitas mematuhi peraturan dan perundang-undangan yang berlaku pada entitas. Pengawasan atas aset tetap harus selalu diperhatikan oleh entitas, sebab jika terdapat kesalahan pengelolaan aset karena kurangnya perhatian dari entitas akan membawa pengaruh pada kegiatan ekonomi dan juga merugikan entitas. Sebaliknya apabila pengawasan terhadap aset dilaksanakan dengan baik akan memberikan keuntungan yang besar bagi entitas.

\section{Landasan Teori \\ 2.1. Aset Tetap}

Aset tetap adalah aset yang memiliki karakteristik sebagai berikut :

a. Memiliki wujud fisik

b. Diperoleh untuk dipergunakan dalam kegiatan usaha entitas dan tidak dimaksudkan untuk dijual.

c. Memberikan manfaat untuk periode jangka panjang dan merupakan subjek depresiasi.

Entitas menggunakan berbagai macam aset seperti peralatan, perabotan, alat-alat, mesin mesin, bangunan dan tanah. Aset tetap (fixed assets) merupakan aset jangka panjang atau aset yang relative permanen. Aset tersebut dimiliki dan digunakan oleh entitas serta tidak dimaksudkan untuk dijual sebagai bagian dari operasi normal.
Aset jangka panjang yang dibeli untuk dijual kembali sebagai bagian dari bisnis normal tidak diklasifikasikan sebagai aset tetap dari sifatnya yang permanen atau lamanya waktu aset tersebut berada dalam persediaan. Terdapat perbedaan yang jelas antara aset tetap dengan barang dagangan. Aset tetap digunakan untuk kegaitan operasi entitas dan tidak dimaksudkan untuk dijual kembali, sedangkan barang dagangan tidak digunakan untuk kegiatan operasi entitas melainkan untuk dijual kembali.

Pernyataan Standar Akuntansi Keuangan (PSAK) No. 16 (revisi 2011:16.2), mendefinisikan aset tetap sebagai berikut:

"Aset tetap adalah aset berwujud yang dimiliki untuk digunakan dalam produksi atau penyediaan barang atau jasa untuk direntalkan kepada pihak lain atau untuk tujuan administratif dan diharapkan untuk digunakan selama lebih dari satu periode."

Dalam buku Akuntansi Suatu Pengantar (Soemarso, 2005) mengatakan bahwa:

"Aset tetap adalah aset tetap berwujud yang masa manfaatnya lebih dari satu tahun, digunakan dalam kegiatan entitas yang dimiliki tidak untuk dijual kembali dalam kegiatan normal entitas serta memiliki nilai yang cukup besar. Sehingga aset tetap merupakan aset jangka panjang yang dimaksudkan untuk digunakan dalam kegiatan normal entitas serta mengandung kekayaan entitas."

\subsection{Sistem Manajemen Basis Data}

Basis data adalah kumpulan data yang terstruktur dan saling berkaitan, berupa suatu file computer. Manajemen basis data adalah program komputer untuk menyimpan dan mengelola secara efektif basis data/data terstruktur tersebut. Pengumpulan data dilakukan untuk membentuk basis data, biasanya berisi informasi tentang entitas atau organisasi. Tujuan utama dari sistem manajemen basis data menyediakan lingkungan yang nyaman dan efisien untuk pengambilan informasi dari basis data dan ke pengguna dengan cepat dan lengkap.

Sistem basis data didisain untuk menangani informasi yang besar dan senantiasa berkembang secara berkala. Manajemen data melibatkan pendefinisian struktur penyimpanan informasi, penyediaan mekanisme pengolahan dan pemanfaatan informasi, pengamanan bagi informasi terhadap kerusakan dan pencegahan pengaksesan oleh orang yang tidak berwenang. Karena sangat pentingnya suatu informasi bagi kebanyakan organisasi, maka basis data mempunyai nilai yang tinggi. Tujuan sistem basis data diantaranya adalah untuk :

* Menghindari duplikasi dan inkonsistensi.

* Memudahkan akses data dan mengingkatkan keamanan.

Komponen basis data diantaranya :

a. Enterprise (entitas)

b. Entitas (entity) adalah suatu objek yang informasinya tercatat

c. Atribut/Unsur Data/Field adalah bagian yang menjelaskan entity 
d. Nilai Data/Data Value, yakni data pada setiap unsur data

e. Unsur Data sebagai "Key" antara lain :

- Primary Key adalah suatu data yang mengidentifikasi record secara unik untuk mengkaitkan beberapa table informasi

- Secondary Key adalah data item yang tidak unik mengidentifikasi record, tetapi mengidentifikasi bebrapa record yang mempunyai cirri sama pada setiap grup record

- Record Data adalah kumpulan unsur data

- File Data adalah kumpulan record data

\section{Metodologi Penelitian}

\subsection{Teknik Wawancara}

Teknik ini dilakukan dengan cara diskusi dan tanya jawab kepada pihak-pihak terkait dengan aset tetap. Hal ini lebih difokuskan kepada bagian logistik dan bagian akuntansi. Bagian logistik yang merupakan diberi kewenangan penuh untuk mengelola dan mengawasi aset tetap.

\subsection{Teknik Observasi}

Pada teknik ini melakukan pemantauan langsung terhadap objek-objek aset tetap. Perolehan data dilakukan dengan data primer dikarenakan belum tersedianya informasi pencatatan semua aset tetap pada Sekolah High Scope Indonesia.

\subsection{Dokumentasi}

Data yang diperoleh dari dokumen-dokumen yang dimiliki oleh entitas yang berhubungan dengan masalah penelitian, untuk memperoleh data berupa daftar aset tetap.

\subsection{Teknik Analisa Data}

Pada teknik ini penulis menggunakan teknik kualitatif (deskriptif) dengan menggunakan alat bantu perancangan sistem seperti Data Flow Diagram (DFD) dan Entity Relationship Diagram (ERD).

\section{Hasil dan Analisa}

Mendesain basis data diharapkan dapat menjelaskan semua aktivitas dengan baik sehingga hasil yang diinginkan sesuai dengan keinginan pengguna dan diharapkan pula dapat meminimalkan kekurangan dan kelemahan sistem yang ada saat ini. akan :

Dengan adanya desain basis data diharapkan

a. Meningkatkan kecepatan informasi yang dihasilkan dan efisiensi dalam pengolahan data.

b. Memperoleh keakuratan data yang dapat dipertanggungjawabkan.

c. Memperkecil persentase kerusakan (hilang atau hancur) data.

Dengan desain basis data terhadap aset tetap diharapkan akan mampu mengolah aset dimulai dari proses permintaan aset sampai proses inventaris dan termonitornya keberadaan dan kondisi aset.

Menggunakan basis data berguna dalam penyimpanan data dengan jumlah data relative banyak sehingga dapat mempermudah penyimpanan, pencarian, pengubahan serta penghapusan data.

Perancangan sistem merupakan mendesain langkah-langkah operasi dalam proses pengolahan data dan prosedur untuk mendukung operasi sistem. Adapun langkah-langkah dalam perancangan sistem pada sistem informasi aset tetap ini adalah mempergunakan model Data Flow Diagram (DFD) dan model Entity Relationship Diagram (ERD).

\subsection{Model Data Flow Diagram (DFD)}

Dalam penjabarannya Data Flow Diagram (DFD) terdiri dari Diagram Konteks dan Diagram Zero .

Berikut Diagram Konteks untuk sistem informasi aset tetap pada Sekolah HighScope Indonesia.

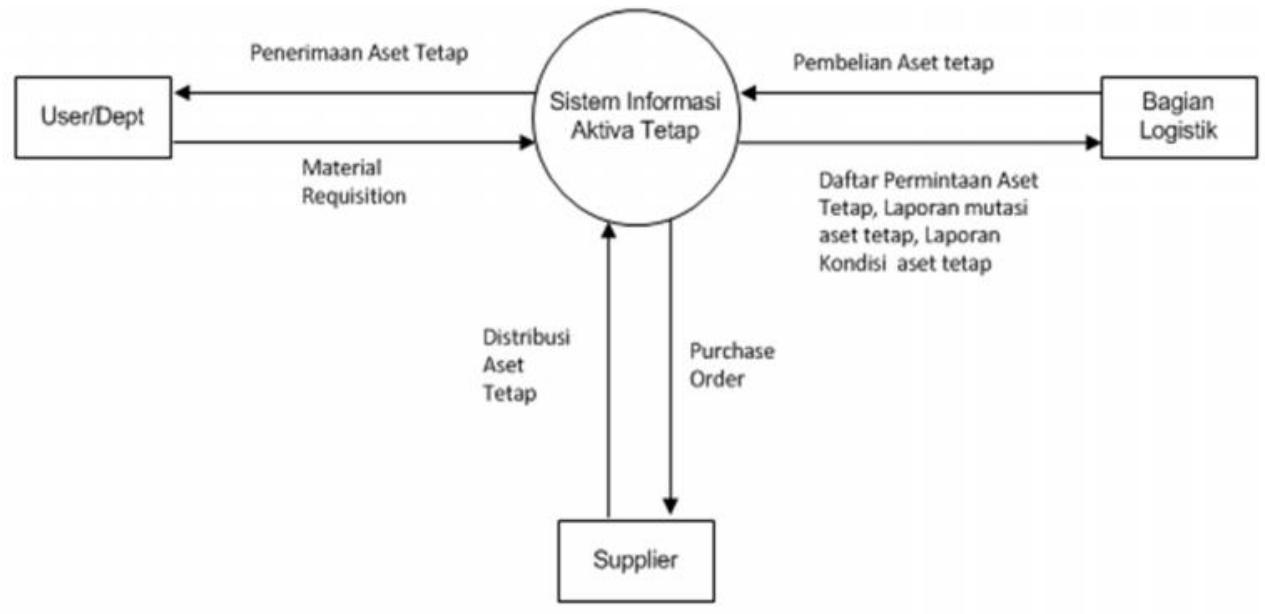

Gambar 1 Model Data Flow Diagram 
Berikut Diagram Zero untuk sistem informasi aset tetap pada Sekolah HighScope Indonesia.

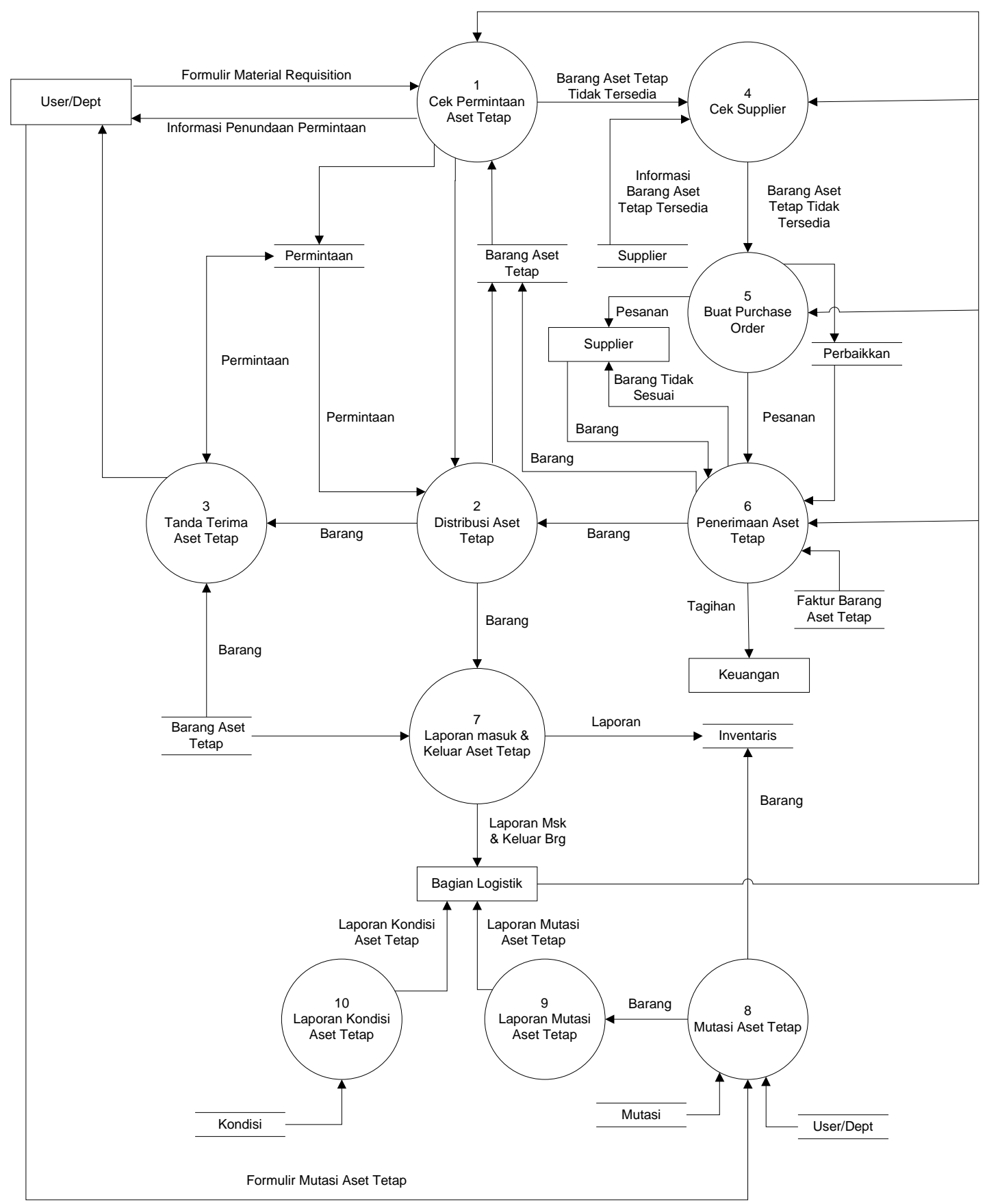

Gambar 2 Diagram Zero

Penjelasan Diagram Zero :

- User/Dept mengisi permohonan permintaan pengadaan aset tetap pada sistem informasi aset tetap yang disetujui oleh departemen head. Bila ada informasi penundaan akan diberitahu kepada user/dept (proses 1)

Bagian logistik akan memeriksa dan memproses permintaan kebutuhan pengadaan barang user/dept pada sistem informasi aset tetap. Bila barang yang diminta tersedia di bagian logistik maka bagian logistik akan memproses pendistribusiaan barang tersebut ke user/dept. Bagian logistik juga akan memproses tanda terima barang aset tetap. (proses 1, 2 dan 3)

Bila barang yang diminta tidak tersedia di bagian logistik maka akan dilakukan pembelian via supplier. Bagian logistik akan mencari nama supplier pada database supplier pada sistem informasi aset tetap. Bagian logistik akan membuat minimal 3 supplier untuk sebagai pembanding harga dan cara pembayarannya. Kemudian bagian logistik akan membuat purchase requisition 
setelah mendapatkan pembanding dan cara pembayarannya yang sesuai dengan ketentuan yang berlaku di Sekolah HighScope Indonesia. (proses 4)

Setelah purchase requisition disetujui oleh direksi, bagian logistik akan membuat purchase order untuk diberikan kepada supplier yang terpilih. (proses 5 )

Proses penerimaan aset tetap dari supplier dilakukan oleh bagian logistik dengan memeriksa spesifikasi, berfungsi atau tidaknya aset tersebut. Jika barang telah sesuai, akan dilakukan proses pembayaran ke supplier. Tagihan dan tanda terima barang aset tetap diberikan ke bagian keuangan untuk diproses. Kemudian bagian logistik akan mencatat dan memberi kode aset tetap di sistem dan pada aset tetap baru. (proses 6)

Barang aset tetap yang masuk atas penerimaan dari supplier dan barang aset tetap yang keluar atas didistribusikannya aset tersebut kepada user/departemen akan dibuat laporannya (proses 7).
Bila aset tetap yang sudah ada dan akan dipindahkan tempat di departemen lain maka harus mengisi pada sistem informasi aset tetap.

Dalam hal ini haruslah melalui persetujuan dari bagian logistik (proses 8).

- Atas terjadinya mutasi aset tetap diantara departemen maka dibuat laporan mutasi aset tetap yang berguna untuk bagian logistik (proses 9)

Adanya kegiatan dan laporan status kondisi aset tetap yang bermanfaat untuk bagian logistik (proses 10)

\subsection{Model Entity Relationship Diagram (ERD)}

Diagram Entity Relationship merupakan jaringan yang menggunakan susunan data yang disimpan dari sistem secara abstrak. Diagram Entity Relationship ini ditemukan oleh Chen Tahun 1976. Tujuan dari Entity Relationship adalah untuk menunjukkan objek data dan relationship yang ada pada objek tersebut. Disamping itu Model ER ini merupakan salah satu alat untuk perancangan dalam basis data. Dalam pengembangan sistem informasi aset tetap berikut merupakan diagram ERDnya.

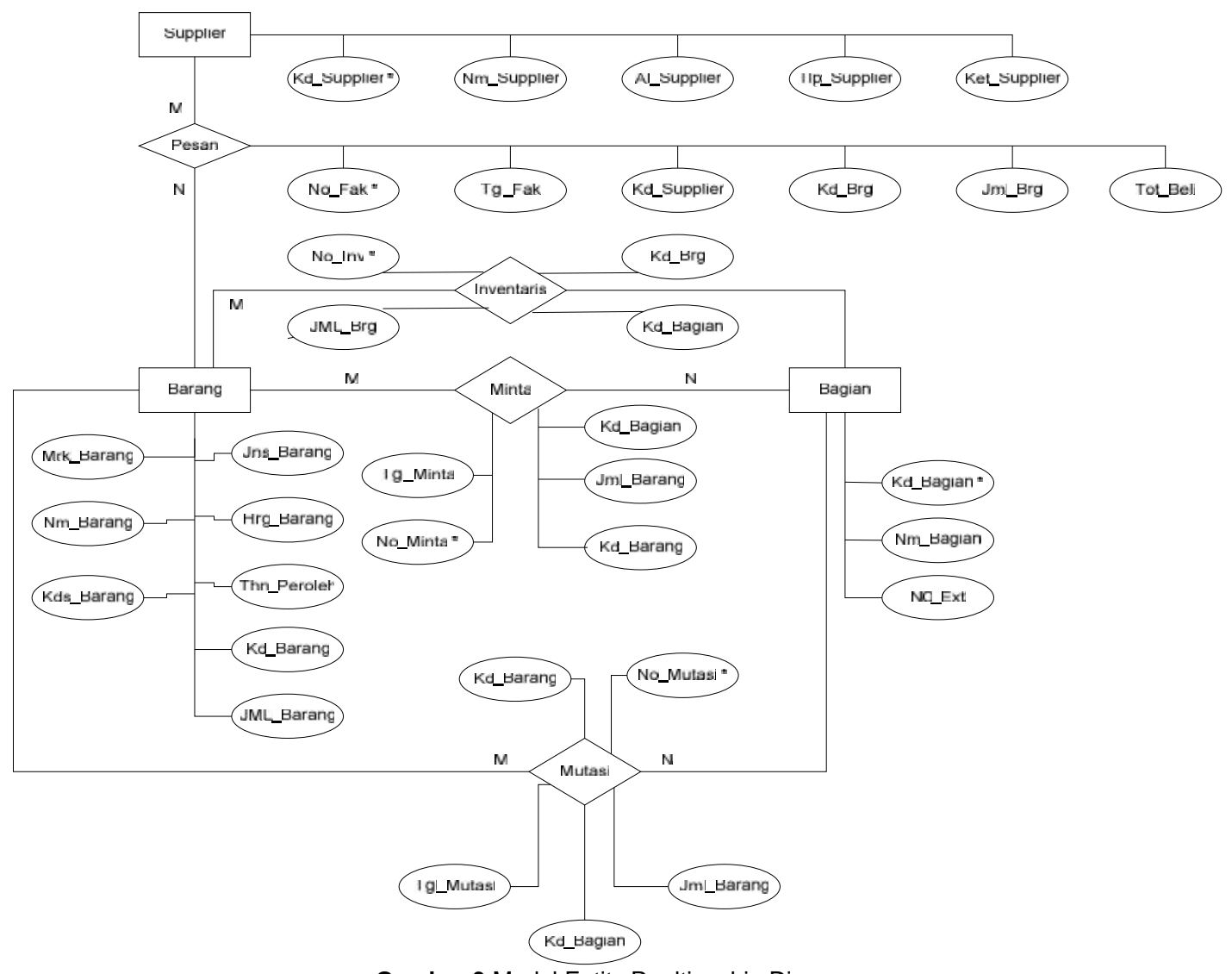

Gambar 3 Model Entity Realtionship Diagram

Dari diagram ERD diatas dapat dipaparkan sebagai berikut :

1. Bebarapa barang dapat dipesan dari beberapa vendor dan beberapa vendor dapat menerima pesanan lebih dari satu barang.

2. Beberapa barang dapat dijadikan aset tetap oleh beberapa bagian tetapi hanya satu bagian yang dapat memiliki satu nomer aset tetap.

3. Beberapa barang dapat didistribusikan ke beberapa bagian dan beberapa bagian dapat menerima distribusi lebih dari satu bagian. 
4. Beberapa barang dapat dimutasikan ke beberapa bagian dan beberapa bagian dapat juga memutasikan lebih dari satu barang.

\subsection{Struktur Kode Aset tetap}

Pemberian struktur kode pada aset tetap bertujuan agar dapat memberikan informasi lengkap mengenai aset tetap. Informasi tersebut mencerminkan golongan aset tetap, lokasi aset tetap, tahun perolehan dan lain-lain.

Struktur kode aset tetap pada sekolah HighScope Indonesia disajikan dengan struktur sebagai berikut :

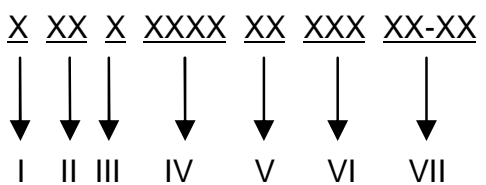

I. Satu digit pertama merupakan struktur kode aset tetap untuk menunjukkan kode kepemilikan entitas. Kode kepemilikan entitas dijabarkan sebagai berikut :

Kode 1 untuk PT. HighScope Indonesia

Kode 2 untuk PT. SHI Bina Belia

Kode 3 Untuk PT. SHI Bina Dasar

Ke tiga entitas tersebut diatas beroperasi di sekolah HighScope Indonesia di Jl. TB. Simatupang. Dimana tiap entitas ada pembelian aset tetap dalam menunjang aktivitas operasional entitasnya.

II. Dua digit kedua merupakan struktur kode aset tetap untuk menunjukkan kode departemen. Tiap departemen memiliki aset tetap dalam menunjang kegiatan operasional departemennya masing-masing. Kode tiap departemen dijabarkan sebagai berikut :

Tabel 1 Kode Departemen

\begin{tabular}{|c|l|c|l|}
\hline Kode & \multicolumn{1}{|c|}{ Nama } & Kode & \multicolumn{1}{c|}{ Nama } \\
\hline Departemen & \multicolumn{1}{|c|}{ Departemen } & Departemen & \multicolumn{1}{c|}{ Departemen } \\
\hline 01 & BOD & 07 & Business Management \\
\hline 02 & Internal Audit & 08 & IT \\
\hline 03 & College Counselor & 09 & Food Service \\
\hline 04 & Library & 10 & HRD \\
\hline 05 & Admission & 11 & Finance Accounting \\
\hline 06 & Clinic & 12 & Logistik \\
\hline
\end{tabular}

III. Satu digit ketiga merupakan struktur kode aset tetap untuk menunjukkan kode lokasi pada bangunan gedung. Kode lokasi bangunan gedung dijabarkan sebagai berikut :

Kode 1 untuk lokasi bangunan gedung 1

Kode 2 untuk lokasi bangunan gedung 2

Kode 3 untuk lokasi bangunan Annex

IV. Empat digit keempat merupakan struktur kode aset tetap untuk menunjukkan kode lokasi lantai dan ruangan pada sebuah bangunan gedung.

Kode lokasi lantai dan ruangan pada sebuah bangunan gedung dijabarkan sebagai berikut :
Tabel 2 Kode Lokasi

\begin{tabular}{|c|c|}
\hline $\begin{array}{c}\text { Kode } \\
\text { Lokasi }\end{array}$ & \multicolumn{1}{|c|}{ Nama Lokasi } \\
\hline 1101 & Lantai 1 Ruangan 101 \\
\hline 1204 & Lantai 1 Ruangan 204 \\
\hline 2423 & Lantai 2 Ruangan 423 \\
\hline 2216 & Lantai 2 Ruangan 216 \\
\hline 3201 & Lantai 3 Ruangan 201 \\
\hline
\end{tabular}

V. Dua digit kelima merupakan struktur kode aset tetap untuk menunjukkan kode kategori aset tetap. Kode kategori aset tetap dijabarkan sebagai berikut :

Tabel 3 Kode Aset Tetap

\begin{tabular}{|c|l|c|l|}
\hline Kode & \multicolumn{1}{|c|}{ Nama } & Kode & \multicolumn{1}{c|}{ Nama } \\
\hline Katogori Ak. Tetap & \multicolumn{1}{|c|}{ Katogori Ak. Tetap } & Katogori Ak. Tetap & Katogori Ak. Tetap \\
\hline 01 & Tanah & 12 & Peralatan dan Perabot Kelas \\
\hline 02 & Bangunan & 13 & Peralatan Bermain \\
\hline 03 & Sarana dan Prasarana & 14 & Peralatan Olah Raga \\
\hline 04 & Mesin dan Instalasi & 15 & Peralatan Musik \\
\hline 05 & Kendaraan & 16 & Peralatan Dapur/Cafetaria \\
\hline 11 & Peralatan dan Perabot Kantor & & \\
\hline
\end{tabular}

VI. Tiga digit keenam merupakan struktur kode aset tetap untuk menunjukkan kode sub dari kategori aset tetap. Kode sub dari kategori aset tetap dijabarkan sebagai berikut :

Tabel 4 Kode Sub Aset Tetap

\begin{tabular}{|c|l|c|l|}
\hline Kode Sub & \multicolumn{1}{|c|}{ Nama Sub } & Kode Sub & \multicolumn{1}{c|}{ Nama Sub } \\
\hline Katogori Ak. Tetap & \multicolumn{1}{|c|}{ Katogori Ak. Tetap } & Katogori Ak. Tetap & \multicolumn{1}{c|}{ Katogori Ak. Tetap } \\
\hline 401 & Komputer & 502 & Whiteboard \\
\hline 402 & AC & 503 & Clipboard \\
\hline 403 & Infocus & 501 & Frozen \\
\hline 404 & Mesin Hitung Uang & 902 & Kulkas \\
\hline 405 & Meja Kerja & 903 & Meja Dapur \\
\hline 501 & Meja Kelas & & \\
\hline
\end{tabular}

VII. Empat digit ketujuh merupakan struktur kode aset tetap untuk menunjukkan perolehan pembelian aset tetap. Kode perolehan pembelian aset tetap dijabarkan sebagai berikut :

Tabel 5 Perolehan Pembelian Aset Tetap

\begin{tabular}{|c|c|}
\hline Kode Perolehan & \multicolumn{1}{|c|}{ Penjelasan } \\
\hline Aktiva Tetap & Perolehan \\
\hline $11-06$ & Perolehan Bulan November Tahun 2006 \\
\hline $07-07$ & Perolehan Bulan Juli Tahun 2007 \\
\hline $09-08$ & Perolehan Bulan September Tahun 2008 \\
\hline $12-08$ & Perolehan Bulan Desember Tahun 2008 \\
\hline $05-12$ & Perolehan Bulan Mei Tahun 2012 \\
\hline $02-13$ & Perolehan Bulan Februari Tahun 2013 \\
\hline
\end{tabular}

\subsection{Pengkodean Suplier}

Dalam pemberian kode pada supplier bertujuan untuk memberikan informasi lengkap data supplier. Informasi tersebut akan memudahkan user untuk mencari supplier yang sesuai dengan kebutuhan entitas. Berikut merupakan kode supplier untuk Sekolah HighScope Indonesia : 
Tabel 6 Kode Supplier

\begin{tabular}{|c|c|c|}
\hline NO & & KETERANGAN \\
\hline 1 & $\begin{array}{l}\text { Kode Supplier } \\
\text { Nama Supplier } \\
\text { Alamat Supplier } \\
\text { Kontak Person } \\
\text { Telepon } \\
\text { NPWP } \\
\text { Tipe Supplier } \\
\end{array}$ & $\begin{array}{l}: \text { SU-0001 } \\
: \text { CV. Adiperkasa } \\
: \text { J1. Rambutan No. } 5 \text { Jakarta Timur } \\
: \text { Ibu Diah } \\
: \text { 021- } 85036542 \\
: \\
: \text { ATK }\end{array}$ \\
\hline 2 & $\begin{array}{l}\text { Kode Supplier } \\
\text { Nama Supplier } \\
\text { Alamat Supplier } \\
\text { Kontak Person } \\
\text { Telepon } \\
\text { NPWP } \\
\text { Tipe Supplier } \\
\end{array}$ & $\begin{array}{l}: \text { SU-0002 } \\
: \text { PT. INK Multimedia } \\
: \text { J1. Persahabatan No. } 106 \text { Jakarta Barat } \\
: \text { Bp. Nugroho } \\
: 021-4687265 \\
: \\
: \text { Tinta Printer }\end{array}$ \\
\hline
\end{tabular}

\subsection{Output Desain Sistem Basis Data}

Ada 8 buah file database yang akan digunakan dalam pembuatan perancangan sistem informasi aset tetap. File dan tabel tersebut adalah sebagai berikut :

\section{FILE BARANG}

File barang berisi untuk menyimpan data informasi barang aset tetap. Primary key dari barang aset tetap adalah kode barang. Kode barang dari setiap barang aset tetap berbeda dengan kode barang aset tetap lainnya.

Tabel 7 File Barang

\begin{tabular}{|r|l|r|l|l|}
\hline No & \multicolumn{1}{|c|}{ Field Name } & Size & Type & Key \\
\hline 1 & Kode Barang & 25 & Numerik & $*$ \\
\hline 2 & Nama Barang & 25 & Text & \\
\hline 3 & Jenis Barang & 25 & Text & \\
\hline 4 & Merek & 25 & Text & \\
\hline 5 & Tahun Perolehan & 4 & Date & \\
\hline 6 & Kondisi Barang & 10 & Text & \\
\hline 7 & Jumlah Barang & 6 & Numerik & \\
\hline 8 & Harga Barang & 25 & Numerik & \\
\hline
\end{tabular}

\section{FILE BAGIAN}

File bagian berisi untuk menyimpan data informasi bagian-bagian yang ada pada entitas. Primary key pada file bagian adalah Kode Bagian.

Tabel 8 File Bagian

\begin{tabular}{|r|l|r|l|l|}
\hline No & \multicolumn{1}{|c|}{ Field Name } & \multicolumn{1}{c|}{ Size } & Type & Key \\
\hline 1 & Kode Bagian & 25 & Numerik & $*$ \\
\hline 2 & Nama Bagian & 25 & Text & \\
\hline 3 & No Extention & 25 & Numerik & \\
\hline
\end{tabular}

\section{FILE SUPPLIER}

File supplier berisi untuk menyimpan data informasi supplier-supplier. Supplier-supplier ini dapat dikelompokkan berdasarkan jenis supplier sehingga kode supplier dibuat sebagai primary key.

Tabel 9 File Supplier

\begin{tabular}{|r|l|r|l|l|}
\hline No & \multicolumn{1}{|c|}{ Field Name } & \multicolumn{1}{c|}{ Size } & Type & Key \\
\hline 1 & Kode Supplier & 25 & Numerik & $*$ \\
\hline 2 & Nama Supplier & 25 & Text & \\
\hline 3 & No Telepon & 25 & Numerik & \\
\hline 4 & Alamat Supplier & 25 & Text & \\
\hline 5 & Keterangan & 25 & Text & \\
\hline
\end{tabular}

\section{FILE PERMINTAAN}

File permintaan berisi untuk menyimpan pengajuan pembelian barang aset tetap dari setiap bagian. Setiap bagian dapat mengajukan lebih dari satu permintaan barang aset tetap. Primary key file ini adalah No Permintaan.

Tabel 10 File Permintaan

\begin{tabular}{|r|l|r|l|l|}
\hline No & \multicolumn{1}{|c|}{ Field Name } & Size & \multicolumn{1}{|c|}{ Type } & Key \\
\hline 1 & No Permintaan & 25 & Numerik & $*$ \\
\hline 2 & Tanggal Permintaan & 10 & Date & \\
\hline 3 & Kode Barang & 25 & Text & \\
\hline 4 & Kode Bagian & 25 & Text & \\
\hline 5 & Jumlah Barang & 7 & Numerik & \\
\hline
\end{tabular}

\section{FILE PEMBELIAN}

File pembelian berisi untuk meyimpan data informasi perihal barang aset yang dibeli. Satu supplier dapat menyediakan beberapa barang aset tetap. Primary key pada file ini adalah no faktur, kode supplier dan kode barang.

Tabel 11 File Pembelian

\begin{tabular}{|r|l|r|l|l|}
\hline No & \multicolumn{1}{|c|}{ Field Name } & Size & Type & Key \\
\hline 1 & No Faktur & 25 & Numerik & $*$ \\
\hline 2 & Tanggal Faktur & 10 & Date & \\
\hline 3 & Kode Supplier & 25 & Numerik & $*$ \\
\hline 4 & Kode Barang & 25 & Numerik & $*$ \\
\hline 5 & Total Pembelian & 4 & Numerik & \\
\hline 6 & Jumlah Barang & 7 & Numerik & \\
\hline 7 & Harga Barang & 25 & Numerik & \\
\hline
\end{tabular}

\section{FILE MUTASI}

File mutasi berisi untuk menyimpan perpindahan mutasi barang aset tetap dari satu bagian ke bagian yang lain. Dengan adanya informasi ini maka keberadaan suatu barang aset tetap dapat diketahui. Pada file ini terdapat 3 (tiga) primary key yaitu no mutasi, kode bagian dan kode barang.

Tabel 12 File Mutasi

\begin{tabular}{|r|l|r|l|l|}
\hline No & \multicolumn{1}{|c|}{ Field Name } & Size & Type & Key \\
\hline 1 & No Mutasi & 25 & Numerik & $*$ \\
\hline 2 & Kode Bagian & 25 & Numerik & $*$ \\
\hline 3 & Kode Barang & 25 & Numerik & $*$ \\
\hline 4 & Tanggal Mutasi & 10 & Date & \\
\hline 5 & Jumlah Barang & 7 & Numerik & \\
\hline 6 & Keterangan & 25 & Text & \\
\hline
\end{tabular}

\section{FILE KONDIS}

File kondisi berisi untuk untuk meyimpan informasi perihal kondisi dari suatu barang aset tetap pada suatu bagian. Pemeriksaan kondisi barang aset tetap dilakukan setiap kahir bulan. Hal ini berfungsi untuk mengetahui apakah barang aset tetap suatu bagian masih bisa dipakai atau tidak.

Pada file ini terdapat 2 primary key yaitu kode bagian dan kode barang. 
Tabel 13 File Kondisi

\begin{tabular}{|r|l|r|l|l|}
\hline No & \multicolumn{1}{|c|}{ Field Name } & \multicolumn{1}{c|}{ Size } & Type & Key \\
\hline 1 & Kode Bagian & 25 & Numerik & $*$ \\
\hline 2 & Kode Barang & 25 & Numerik & $*$ \\
\hline 3 & Tanggal Kondisi & 10 & Date & \\
\hline 4 & Kondisi & 10 & Text & \\
\hline 5 & Keterangan & 25 & Text & \\
\hline
\end{tabular}

\section{FILE ASET}

File asset berisi untuk menyimpan informasi kegiatan pendistribusian barang aset tetap sejak dari permintaan sampai kepada bagian yang menerima barang tersebut. Sehingga manajemen entitas mengetahui pengadaan barang aset tetap berdasarkan dari nomer permintaan bagian mana dan nomer faktur.

Tabel 14 File Aset

\begin{tabular}{|r|l|r|l|l|}
\hline No & \multicolumn{1}{|c|}{ Field Name } & Size & \multicolumn{1}{|c|}{ Type } & Key \\
\hline 1 & Nomer Inventaris & 25 & Numerik & $*$ \\
\hline 2 & Tanggal Inventaris & 10 & Date & \\
\hline 3 & Nomer Faktur & 25 & Numerik & $*$ \\
\hline 4 & Kode Bagian & 25 & Numerik & $*$ \\
\hline 5 & Kode Barang & 25 & Numerik & $*$ \\
\hline 6 & Nomer Permintaan & 25 & Numerik & $*$ \\
\hline 7 & Tanggal Pembelian & 10 & Date & \\
\hline 8 & Jumlah Aset & 15 & Numerik & \\
\hline 9 & Nilai Aset & 25 & Numerik & \\
\hline
\end{tabular}

\section{Kesimpulan dan Saran}

\subsection{Kesimpulan}

Desain sistem manajemen basis data aset tetap pada Sekolah HighScope Indonesia yang telah dirancang agar ke depannya dapat memudahkan pekerjaan dalam :

> Tersedianya catatan informasi pengadaan barang aset tetap dari sejak permintaan sampai pendistribusiannya.

> Pelaporan secara periodik dan terperinci kondisi barang aset tetap. Laporan ini juga berfungsi untuk menilai aset yang dimiliki oleh entitas.

$>$ Pelaporan secara periodik keberadaan dari suatu aset tetap, dan

> Perancangan ini belum diuji coba sehingga belum diketahui ada atau tidaknya kesalahan pada rancangan database aset tetap.

\subsection{Saran}

> Perlu diuji cobakan terhadap desain sistem manajemen basis data aset tetap yang telah dibuat.

> Adanya kebijakan dari Top Manajemen sekolah HighScope Indonesia untuk dapat mengimplementasikan desain sistem manajemen basis data aset tetap..

> Perlunya penelitian lebih lanjut dari desain manajemen basis data aset tetap ini untuk di implementasikan yang berbasiskan web

\section{DAFTAR PUSTAKA}

Adita Ayu Prawiyanti dan Ramadhian Agus Tritono, 2013, Perancangan Sistem Informasi Inventaris Program Studi Teknik Informatika Universitas Surakarta, Seminar Riset Unggulan Nasional Informatika dan Komputer FTI UNSA Vol 2 No 1 - Maret 2013 ISSN : $2302-1136$

Ahmad Sahrizal dan Febriliyan Samopa, 2012, Pengembangan Aplikasi Sistem Informasi Akuntansi dan Pengelolaan Keuangan Negara Modul Aset Tetap Menggunakan Bahasa Pemrograman Java dan Database PostgreSQL, Jurnal Teknik ITS Vol 1 September 2012 ISSN : 2301 - 9271

Andi Kristanto. 2008. Perancangan Sistem Informasi dan Apilkasinya. Gava Media. Yogyakarta.

Andi Nirwana, 2010, Perancangan Sistem Informasi Inventaris Berbasis Client Server Pada STMIK Handayani Makasar, Jurnal IT STMIK Handayani Makasar Vol 1 Desember 2010

Heri Sufriana, Ir. Aris Tjahyanto, M. Kom, 2010, Analisa Dan Desain Sistem Informasi Aset Tetap Dan Persediaan Pada PDAM Kabupaten Magetan, Makalah Seminar Nasional, Institut Teknologi Sepuluh November Surabaya

Jogiyanto, Hartono, 2005, Analisis \& Desain Sistem Informasi Pendekatan Terstruktur Teori dan Praktek Aplikasi Bisnis, Andi Yogyakarta

Kartika Pertiwi, Kodrat I. S dan Maman Somantri, 2013, Sistem Informasi Manajemen Aset Di Fakultas Teknik Universitas Dipenogoro, Transient Vol. 2 No. 1 Maret 2013 ISSN : 2302-9927, 40

Mcleod Jr, Raymond, 2008, Sistem Informasi Manajemen, Jakarta, Penerbit Salemba Empat

Pernyataan Standar Akuntansi Keuangan (PSAK) No. 16 (Revisi 2011), Aset Tetap, Ikatan Akuntan Indonesia.

SR Soemarso 2005, Akuntansi Suatu Pengantar Buku 2 Edisi 5, Jakarta, Salemba Empat

Tities Sumunaring Tyas dan Ali Tarmuji, 2013, Perancangan Enterprise Architecture Planning (EAP) Pada Proses Manajemen Aset Dengan Zachman Framework (Studi Kasus Divisi Manajemen Fasilitas $P T$. $X Y Z$ ), Jurnal Sarjana Teknik Informatika Vol 1 No 1 Juni 2013 eISSN : $2338-5197$

Windarto, 2012, Analisa Dan Rancangan Sistem Informasi Inventarisasi Logistik Pada Koperasi Pegawai Telkom Barata, No Makalah : 338, Proceedings Konferensi Nasional Sistem Informasi STMIK - STIKOM Bali 23-25 Febrauri 2012 ISBN : 9786029876802 